\title{
Journal of Mammalogy
}

\section{Anthropogenic disturbance and chimpanzee (Pan troglodytes) habitat use in the Masito-Ugalla Ecosystem, Tanzania}

\begin{tabular}{|r|l|}
\hline Journal: & Journal of Mammalogy \\
\hline Manuscript ID & JMAMM-2020-054.R3 \\
\hline Manuscript Type: & Feature Article \\
\hline Complete List of Authors: & $\begin{array}{l}\text { Maijo, Simula; Tanzania Wildlife Research Institute, N/A; The Nelson } \\
\text { Mandela African Institution of Science and Technology, School of Life } \\
\text { Sciences and Bio-engineering } \\
\text { Piel, Alexander; Liverpool John Moores University, School of Biological } \\
\text { and Environmental Sciences; Greater Mahale Ecosystem Research and } \\
\text { Conservation, N/A } \\
\text { Treydte, Anna; The Nelson Mandela African Institution of Science and } \\
\text { Technology, School of Life Sciences and Bio-engineering; University of } \\
\text { Hohenheim, Agroecology in the Tropics and Subtropics }\end{array}$ \\
\hline Keywords: & $\begin{array}{l}\text { Anthropogenic disturbance, habitat use, nests, species richness, species } \\
\text { diversity, species abundance }\end{array}$ \\
\hline
\end{tabular}

\section{SCHOLARONE" Manuscripts}


ChimpanZeE, Disturbance AND Resources

\title{
Anthropogenic disturbance and chimpanzee (Pan troglodytes) habitat use in the Masito-
}

\section{Ugalla Ecosystem, Tanzania}

\author{
Simula P. Maijo*, Alex K. Piel and AnNa C. TReydte
}

Tanzania Wildlife Research Institute, Box 661, Arusha, Tanzania (SPM)

School of Life Sciences and Bio-engineering, The Nelson Mandela African Institution of Science and Technology, Box 447, Tengeru, Arusha, Tanzania (SPM, ACT)

School of Biological and Environmental Sciences, Liverpool John Moores University, Liverpool, United Kingdom (AKP)

GMERC, LTD, Box 66, Kigoma, Tanzania (AKP)

Agroecology in the Tropics and Subtropics, University of Hohenheim, Stuttgart, Germany (ACT) *Correspondent: maijocmla@yahoo.com or simula.maijo@tawiri.or.tz

The habitat quality of chimpanzee (Pan troglodytes), including the availability of plant food and nesting species, is important to ensure the long-term survival of this endangered species.

Botanical composition of vegetation is spatially variable and depends on soil characteristics, weather, topography, and numerous other biotic and abiotic factors. There are few data regarding the availability of chimpanzee plant food and nesting species in the Masito-Ugalla Ecosystem (MUE), a vast area that lies outside national park boundaries in Tanzania, and how the availability of these resources vary with human disturbance. We hypothesized that chimpanzee plant food species richness, diversity, and abundance, decline with increasing human disturbance. Further, we predicted that chimpanzee abundance and habitat use is influenced negatively by human disturbance. Published literature from Issa Valley, Gombe, and Mahale Mountains National Parks, in Tanzania, was used to document plant species consumed by chimpanzees, and quantify their richness, diversity, and abundance, along 32 transects totaling $63.8 \mathrm{~km}$ in length across four sites of varying human disturbance in MUE. We documented 102 chimpanzee plant food species and found a significant differences in their species richness $(H=55.09, P<0.001)$ 
ChimpanzeE, DisturbanCE AND RESOURCES

27 and diversity $(H=36.81, P<0.001)$ across disturbance levels, with the moderately disturbed site

28 exhibiting the highest species richness and diversity. Chimpanzees built nests in 17 different tree

29 species. The abundance of nesting tree species did not vary across survey sites $(H=0.279, P>$

30 0.964). The least disturbed site exhibited the highest encounter rate of chimpanzee nests $\mathrm{km}^{-1}$,

31 with rates declining towards the highly disturbed sites. Our results show that severe

32 anthropogenic disturbance in MUE is associated with the loss of chimpanzee plant food species

33 and negatively influences chimpanzee habitat use, a relationship that threatens the future of all

34 chimpanzee populations outside national parks.

36 Key words: Anthropogenic disturbance, habitat use, nests, species richness, species diversity,

37 species abundance 
Chimpanzee, Disturbance AND Resources

Habitat loss and over-exploitation of natural resources are major challenges for biodiversity conservation (Rands et al. 2010). These processes are driven mainly by human poverty and

42 increasing human population size, which, when combined, result in over-dependence on nature,

43 thus threatening wildlife (Hackel 1999). Increasing human population sizes and encroachment on

44 wildlife habitat are the core incitement of human-wildlife conflicts, habitat fragmentation and

45 loss, and associated biodiversity loss in most areas (Brooks et al. 2002; Fahrig 2003; Hanski

2011). A number of primate species, including chimpanzees (Pan troglodytes), inhabit human-

47 impacted landscapes (Hockings et al. 2012, 2015; Bryson-Morrison et al. 2016, 2017), following

48 the continuous contraction of their natural ranges as a result of human encroachment. To

49 understand how chimpanzees will persist in human encroached landscapes, we need to assess the

50 relationship between chimpanzee habitat degradation and the availability of resources used by

51 this species.

52 The availability and quantity of food resources in chimpanzee habitat is one of the primary

53 factors that drives chimpanzee abundance and distribution (Stevenson 2001; Foerster et al. 2018).

54 Hence, as the density of food resources declines, chimpanzee range tends to increase to

55 compensate for reduced food availability (Baldwin et al. 1982). Alternatively, chimpanzees might

56 instead consume more nutrient-poor foods (Doran 1997; Basabose 2005), which may reduce their

57 fitness and survival. Chimpanzees are omnivorous and feed on fruits, leaves and other plant parts,

58 vertebrates, and invertebrates, as well as on inorganic substances (i.e., termite mound soil and

59 rocks; Goodall 1968; Nishida and Uehara 1983; Newton-Fisher 1999; Nishida 2012; Watts et al.

60 2012a; 2012b; Itoh and Nakamura 2015; Piel et al. 2017). Notwithstanding, chimpanzees

61 predominantly depend on plant matter, especially ripe fruits, which constitute the majority of

62 their diet (Goodall 1968; Nishida 1968; Nishida and Uehara 1983; Nakamura et al. 2013). 


\section{Chimpanzee, Disturbance AND ResourCes}

In addition to food resources, the availability of nesting sites is another key factor influencing chimpanzee presence, abundance, and distribution (Carvalho et al. 2015). Nesting is a daily behaviour in all great ape species (Goodall 1968; Fruth et al. 2018). All weaned great apes, including chimpanzees, build night nests for sleeping, occasionally build daytime nests for resting, and rarely re-use nests (Goodall 1962; Rothman et al. 2006). Although any woody species is a potential nesting site, chimpanzees nest non-randomly wherever the behaviour has been studied (Basabose and Yamagiwa 2002; Hernandez-Aguilar 2009; Stewart et al., 2011; Last and Muh 2013). Chimpanzee nests, therefore, are a good proxy for chimpanzee presence (Hernandez-Aguilar et al. 2013) and reveal chimpanzee habitat use as well as population density and trends (Kühl et al. 2017). Indeed, most approaches for estimating wild chimpanzee populations rely on nest counts (Plumptre and Reynolds 1997; Bonnin et al. 2018). In some areas, chimpanzees occur at low densities and thus nest counts are impracticable over a large area. Nevertheless, recent work using drones (Bonnin et al. 2018), demonstrates the effectiveness of nest counts for population size estimates in wild chimpanzees.

Chimpanzee populations are declining rapidly (Junker et al. 2012), threatened by habitat loss, poaching, disease, and the pet trade (Leendertz et al. 2006; Hockings et al. 2015; Kühl et al. 2017, 2019). In Tanzania, eastern chimpanzees (P. t. schweinfurthii) are distributed across the western region (TAWIRI 2018), with an estimated total population of less than 2,500 individuals (Moyer et al. 2006; Piel and Stewart 2014). More than 75\% of the current population lives outside national parks (Piel et al. 2015a). Chimpanzee numbers outside national parks have significantly declined in the 2000's (Yoshikawa et al. 2008; Ogawa et al. 2013) and a significant sub-population is found in the Masito-Ugalla Ecosystem (MUE - Fig. 1; Moore and Vigilant 2013; Piel et al. 2015a). Surveys across MUE in 2012 revealed a density of 0.1 individuals $\mathrm{km}^{-2}$ 
Chimpanzee, Disturbance AND Resources

(Piel et al. 2015a), and a total population of about 288 individuals, or $>10 \%$ of Tanzania's chimpanzees.

Studies on the relationship between disturbance and primate populations have been conducted on a number of species. Chapman and Chapman (2000) found that anthropogenic disturbance affected the abundance and group size of red colobus and red-tailed guenons in Kibale National Park, Uganda. Cavada et al. (2019) described the relationship between anthropogenic disturbance and the density of arboreal primate species in the Udzungwa Mountains of Tanzania and showed that disturbance negatively affected primate density. Herrera et al. (2011), examining the effects of disturbance on lemurs at Ranomafana National Park, Madagascar, found that anthropogenic disturbance does not always have deleterious effects on primates. The variation in lemur abundance was related to diet (i.e., feeding guilds) rather than disturbance, with frugivorous species more prone to population declines than folivores or insectivores. Moreover, anthropogenic disturbance not only affects primate densities but also their behaviours (Kühl et al. 2019). In most environments where nonhuman primates coexist with people, primates exhibit behavioral flexibility, including dietary adjustments, to survive (McCarthy et al. 2017; McLennan et al. 2017).

There are a number of studies that described chimpanzee diet across western Tanzania (Table 1). However, the only two studies that described chimpanzee diet in MUE were conducted in the Issa Valley, and at Nguye and Bhukalai sites. Based on chimpanzee diet studies across western Tanzania, Yoshikawa and Ogawa (2015) found a proportion (range: 20\% - 39\%) of the identified chimpanzee plant food species to overlap between Nguye, Bhukalai, Gombe, and Mahale Mountains. For example, of 100 plant food species identified in Nguye and Bhukalai, 39\% of the plant food species also were consumed by the Mahale chimpanzees, and $33 \%$ by the Gombe chimpanzees. Out of 198 plant food species identified in Mahale Mountains National Park, 


\section{ChimpanZee, Disturbance AND ResourCes}

110 Nguye and Bhukalai chimpanzees consumed 20\%, and of 147 plant food species identified in

111 Gombe National Park, Nguye and Bhukalai chimpanzees consumed 22\%.

112 While Balcomb et al. (2000) found a positive relationship between the density of fleshy fruit

113 trees and chimpanzee density measured across six sites in Kibale Forest, Uganda, a similar study

114 on plant food availability and habitat disturbance has yet to be conducted at MUE, where

115 anthropogenic disturbance is high (Plumptre et al. 2010; Wilfred and MacColl 2014). Increasing

116 threats from agricultural expansion, settlements, cattle herding, annual fires, logging, and

117 poaching, have been reported in the region and threaten chimpanzee habitat. Given the rate of

118 disturbance across MUE in western Tanzania and the direct result disturbance has on

119 chimpanzees and population-specific cultures (Kühl et al. 2019), a clearer understanding of the

120 relationship between habitat disturbance, resource availability, and chimpanzee abundance, is

121 required.

122 In this study, we compared the availability of chimpanzee plant food and nesting species

123 across four areas within MUE to investigate whether human disturbance levels are associated

124 with chimpanzee plant food species, nesting tree species, and chimpanzee abundance. Following

125 Morgan et al.'s (2018) model of assessing the impact of human activities on great apes and their

126 habitat, we quantified the extent of human disturbance in MUE and related the levels of human

127 disturbance to chimpanzee abundance and resources. We hypothesized first, that chimpanzee

128 plant food species richness, diversity, and abundance, decline with increasing human disturbance.

129 Second, that chimpanzee abundance - as inferred from nest counts - would be negatively

130 associated with human disturbance: we predicted that nest counts would be high in areas of low

131 or no human disturbance. 
ChimpanzeE, DisturbanCE AND ResourCes

\section{Material ANd Methods}

This study was carried out in the MUE at four sites (Issa Valley, Mfubasi, Mlofwesi, and

located in western Tanzania and forms a part of the Greater Mahale Ecosystem (GME), covering an area of 5,756 km² (Piel et al. 2015a). The region is a biodiversity-rich habitat (Moyer et al.

2006) and is protected partly as the Tongwe Forest Reserves (TFRs). Major threats to the region include agriculture, which represents the main economic income-source for people (Mwageni et

Pintea 2012; Wilfred and MacColl 2014). Wilfred and MacColl (2014) reported on the pattern of

142 illegal natural resource exploitation in Ugalla, western Tanzania, and found poaching, logging, 143 and bushmeat hunting, to be the dominant illegal activities.

144 Elevation across MUE ranges from 900 to 1800 masl, with average annual temperatures from 11 to $35^{\circ} \mathrm{C}$ (Piel et al. 2015a) and average annual rainfall between 900 and $1400 \mathrm{~mm}$, mainly

146 falling between November and April (Piel et al. 2015b). The ecosystem is characterized by five

147 different vegetation types: (1) miombo woodland, dominated by Brachystegia spp. and

148 Julbernardia spp., interspersed with (2) seasonally inundated grasslands, (3) rocky outcrops, as 149 well as (4) evergreen riparian and (5) thicket riverine forests (Piel et al. 2017). Open woodland 150 (i.e., more open miombo woodland) is resorted to wooded grassland in this study. Issa Valley, 151 Mfubasi, Mlofwesi, and Mapalamane, vary in protection status. Issa Valley and Mfubasi are 152 located in Tongwe East Forest Reserve, Mlofwesi is located in Tongwe West Forest Reserve, and 153 Mapalamane is located in Mishamo Village Forest, a lower level protection status from the TFRs, 154 which are District forest reserves. Despite the difference in protection status, all the sites 155 experience anthropogenic activities. Issa Valley has an established long-term research presence, 156 which has been shown to deter some human activities (Piel et al. 2015b). In contrast, Mfubasi, 


\section{ChimpanzeE, DisturbanCE AND ResourCes}

157 Mlofwesi, and Mapalamane, all have experienced extensive disturbance over the last ten years 158 (Piel and Stewart 2014).

To survey chimpanzee plant food species, we laid out eight $2 \mathrm{~km}$-long transects radially around a center point established in each study site. We walked approximately $1 \mathrm{~km}$ away from the centre point before starting transects, covering different vegetation types. In some cases, we walked for more than $1 \mathrm{~km}$ until a particular vegetation type was reached. That is, the start point of transects depended on the availability of a particular vegetation type and the direction followed the extension of such vegetation type. Since riparian forests rarely are sited along cardinal directions, we followed these forests regardless of the cardinal direction. Along each transect, we conducted ten vegetation plots of $25 \mathrm{~m} \times 25 \mathrm{~m}$ each, with $200 \mathrm{~m}$ between plots, summing up to $199,375 \mathrm{~m}^{2}\left(0.199 \mathrm{~km}^{2}\right)$ of the total sampled vegetation plot area across survey sites. We did not conduct vegetation plots in cultivated areas. Since most of MUE is miombo woodland with few strips of riparian forest and very few patches of wooded grassland, we used stratified sampling to have sufficient representation of chimpanzee plant food species. The vegetation plots covered

171 wooded grassland, riparian forest, and miombo woodland. A total of $6(2 \%)$ vegetation plots

172 were sampled in wooded grassland, $137(43 \%)$ in riparian forest, and $176(55 \%)$ in miombo 173 woodland. Published literature (Goodall 1968; Wrangham 1975; Nishida and Uehara 1983;

174 Nakamura et al. 2015; Piel et al. 2017) was used to document chimpanzee plant food species 175 (Appendix 1). In each plot, we documented and counted all known chimpanzee plant food 176 species and determined their growth form and diameter at breast height (DBH).

177 We inferred chimpanzee abundance from chimpanzee nest presence (Plumptre and Reynolds 178 1997; Kouakou et al. 2009; Bonnin et al. 2018) and identified nesting tree species. Chimpanzee 179 nests visible along and from transects were counted and recorded, and we established a ten meter 180 radius around any nest to document nearby nests. Chimpanzee nest number served as a proxy for 
ChimpanzeE, DisturbanCE AND ResourCes

181

182

183

184

185

186

187

188

189

190

191

192

chimpanzee abundance as our sample size did not warrant further analyses using DISTANCE to calculate population density (Buckland et al. 2001). Using nest counts as a proxy measure for population density has known limitations. For instance, nest age and nest production rate (both of which influence density calculations) can vary by region and season. However, previous work in Tai Forest, Cote d'Ivoire, that tested the reliability of nest counts with known population sizes demonstrated nest counts as an effective method to document wild chimpanzee population sizes and confirmed that the method produced reasonable density estimates (Kouakou et al. 2009). To quantify anthropogenic disturbance, we documented human activities that interrupted the natural state of chimpanzee habitat. We recorded different human activities based on visible signs along transects and in vegetation plots (Table 2). All signs, e.g., cattle bomas, houses, farms, etc., within $50 \mathrm{~m}$ of transects and plots were documented. We used the presence of houses and people to count households. Agricultural activities was determined based on the cultivated fields and areas cleared for cultivation and obtained the number of different farms based on farm demarcations, whereas visible cattle herds and bomas represented livestock grazing. When more than one sign of different human activities were observed in a single location, e.g., logging on farms, beekeeping on farms, etc., we recorded only the major activities that were presumed to cause the greatest impact on chimpanzee habitat, regardless of the others. In general, we recorded type, frequency, and location, of each event of illegal human activity and assumed that each recorded activity had a different impact on chimpanzee habitat. Based on the presumed impact, we assigned impact scores following Morgan et al. (2018) between 1 (lowest impact) and 5 (highest impact) to all types of human activities observed across MUE (Table 2).

We computed the frequency of anthropogenic evidence by using encounter rates of the signs per kilometer walked. Following Morgan et al. (2018), we multiplied the weighted impact scores by the frequency of encounters of each sign and then summed an overall measure of severity of 


\section{ChimpanzeE, Disturbance AND RESOURCES}

205

206

207

208

209

210

211

212

213

214

215

216

217

218

219

220

221

222

223

224

225

226

227

228

disturbance per site. Based on the disturbance measure, we placed survey sites into four categories, i.e., least disturbed, mildly disturbed, moderately disturbed, and highly disturbed sites (Table 3).

We calculated chimpanzee plant food species richness by counting the total number of plant food species in each vegetation plot and then determined Shannon-Wiener diversity indices. We defined chimpanzee plant food abundance as the total number of individual plant species with $\mathrm{DBH}>10 \mathrm{~cm}$ per site. Based on the hypothesis that chimpanzee plant food species richness, diversity, and abundance, decline with increasing human disturbance, we averaged the values and compared the inter-site values across disturbance categories.

To determine if the data were normally distributed, we carried out a Shapiro-Wilk test followed by a Levene's test for homogeneity of variances (Shapiro and Wilk 1965). We used a Kruskal-Wallis test with Dunn's post hoc test to compare the variation of chimpanzee plant food species richness, diversity, and abundance, among and within sites as the data sets were nonnormal. We also compared chimpanzee plant food species richness, diversity, and abundance across vegetation types. We converted chimpanzee nest number into nests $\mathrm{km}^{-1}$ walked in each survey site and related these proportions to disturbance categories. We carried out all statistical analyses in Paleontological Statistics software (PAST Version 3.20, Hammer et al. 2001)) and for all statistical tests, statistical significance was set at $\mathrm{P}=0.05$.

\section{Results}

The types and frequency of anthropogenic activities differed across survey sites and disturbance categories (Table 3). At Issa Valley (the least disturbed site), anthropogenic signs were old and we observed no active signs during the survey. In Mfubasi (the mildly disturbed site), we documented recent signs of livestock activities, beekeeping, poaching, and logging. At Mlofwesi (the moderately disturbed site) we found evidence of active logging, poaching signs, 
ChimpanzeE, DisturbanCE AND ResourCes

229

230

231

232

233

234

235

236

237

238

239

240

241

242

243

244

245

246

247

248

249

250

251

252

livestock grazing, illegal beekeeping, and commercial beekeeping. In Mapalamane (the highly disturbed site), we observed predominantly active agricultural activities, numerous settlements, and livestock activities. Mapalamane was inhabited with people in established settlements and contained cleared land for cultivation of maize (Zea mays), cassava (Manihot esculenta), tobacco (Nicotiana tabacum), cotton (Gossypium sp.), sunflower (Helianthus sp.), beans (Phaseolus vulgaris), and other crops.

Logging and illegal beekeeping were present across all four survey sites in MUE. Logging threatened Pterocarpus angolensis and P. tinctorius tree species. The latter species is an important food source for chimpanzees (Piel et al. 2017). We observed cut logs of both species in Mfubasi and Mlofwesi sites. We recorded seven locations of already cut logs (range: 1-4 logs) in Mfubasi and eleven locations (range: 1-6 logs) in Mlofwesi. Mlofwesi had a slightly but not significantly higher mean of cut $\operatorname{logs} 3.1(3.1, \mathrm{SE}=0.5)$ than Mfubasi $2.1(2.1, \mathrm{SE}=0.4 ; \mathrm{t}=$ 1.049, $\mathrm{P}=2.119$ ). Illegal beekeeping threatened $J$. globiflora and B. speciformis because local people de-bark these tree species to make local beehives. These two tree species provide chimpanzees with food (Piel et al. 2017) and are important tree species used in nesting.

We identified a total of 102 potential chimpanzee plant food species that occurred within MUE (Appendix 1). Of these plant species, most were trees (62\%), followed by herbs (12\%), shrubs $(9 \%)$, lianas $(8 \%)$, climbers $(7 \%)$, and grasses and palm trees (1\% each). Chimpanzee plant food species richness differed significantly among sites with different disturbance levels $(H$ $=55.09, P<0.001$, Fig. 2), with Mlofwesi and Mapalamane exhibiting the highest richness values. These two sites also exhibited higher chimpanzee plant food diversity compared to the other two $(H=36.81, P<0.001$, Fig. 3). Chimpanzee plant food abundance (i.e., trees, shrubs and liana species with DBH $>10 \mathrm{~cm})$ did not differ significantly across sites $(H=2.477, P=$ 0.478). Riparian forest exhibited chimpanzee plant food species richness that was nearly twice 


\section{Chimpanzee, Disturbance AND ResourCes}

253 that of wooded grassland $(H=33.58, P<0.001$, Fig. 4). Chimpanzee plant food diversity did not 254 differ significantly across vegetation types $(H=1.334, P=0.513)$, however, chimpanzee plant 255 food abundance (i.e., trees, shrubs, and liana, species with $\mathrm{DBH}>10 \mathrm{~cm}$ ) was higher in miombo 256 woodland compared to riparian forest and wooded grassland $(H=9.163, P<0.01)$.

The encounter rates of the number of chimpanzee nests (i.e., nests $\mathrm{km}^{-1}$ ) differed significantly

258 between sites with different disturbance levels. The least disturbed site had the highest encounter 259 rate of chimpanzee nests $\left(8.5\right.$ nests $\left.\mathrm{km}^{-1}\right)$; encounter rates declined considerably towards the 260 highly disturbed site $\left(1.5\right.$ nests $\left.\mathrm{km}^{-1}\right)$. Seventeen different plant species comprised the trees in 261 which all nests were built (Table 4). The abundance of the identified nesting plant species did not 262 vary significantly across sites $(H=0.279, P>0.964)$. Brachystegia boehmii and J. unijugata 263 were the most frequently used nesting species.

\section{DiSCUSSION}

In this study, we compared four sites in the MUE area of western Tanzania to investigate the relationship between anthropogenic disturbance and chimpanzee abundance as well as the 267 availability of chimpanzee plant food species (i.e., species richness, diversity, and abundance) 268 and nesting tree species in each of the sites. In contrast to our hypothesis that chimpanzee plant 269 food species richness, diversity, and abundance, decline with increasing human disturbance, our

270 results indicate that chimpanzee plant food species richness and diversity increased with

271 increasing human disturbance, while abundance did not. However, at the site with the highest

272 level of human disturbance both species richness and diversity declined slightly.

273 Our results are consistent with the intermediate disturbance theory, which suggests that 274 species richness and diversity may increase with disturbance in a particular habitat (Connell 275 1978; Wilkinson 1999; Catford et al. 2012), provided that the extent of disturbance is neither too 


\section{ChimpanZeE, DisturbanCE AND RESOURCES}

276 low nor too severe. Moderate disturbance in a particular habitat creates unstable environments of

277 low competitive exclusion between co-occurring species and, therefore, supports high species

278 richness and diversity (Willig and Presley 2018). In contrast, high disturbance interrupts and

279 eliminates many species in plant communities, resulting in plant communities dominated by few

280 tolerant species, a situation that may result in taxonomic homogenization (Lôbo et al. 2011). The

281 intermediate disturbance theory might explain why Mlofwesi, with moderate disturbance,

282 exhibited higher values of chimpanzee plant food species richness and diversity compared to sites

283 of relatively low disturbance such as Issa Valley and Mfubasi. Mfubasi, Mlofwesi, and

284 Mapalamane have all experienced extensive disturbance over the last ten years (Piel and Stewart 2014) and the latter had the highest occurrence of human activities of severe negative influence

286 (e.g., agriculture and settlement) on chimpanzee habitat, which might have influenced the decline 287 of plant food species richness and diversity. Our results suggest that more individual plant species are lost in areas of severe human disturbance than in areas of low human disturbance.

289 This is in agreement with Köster et al. (2013), who reported that environmental conditions in 290 disturbed habitats do not support a variety of tree species because only few tree species have the 291 capacity to establish in these habitats.

292 Moreover, our results show that human disturbance has not yet had an influence on the 293 abundance of chimpanzee plant food and nesting tree species. This is in contrast to Fuller et al. 294 (1998), who found that human disturbance resulted in changes to forest composition and plant 295 species abundance in New England, USA, which granted was carried out in New England296 Acadian forest habitat, rather than Tropical forest. In this study, we did not set up vegetation 297 plots in cultivated fields and in areas cleared for farming, as these activities only were observed 298 in one of the four survey sites. However, we observed signs of selective logging, livestock 299 grazing and unsustainable beekeeping practices in all survey sites. Since livestock grazing has no 


\section{ChimpanzeE, Disturbance AND RESOURCES}

immediate effect on the abundance of woody plant species (with the exception of cattle bomas, which also were not sampled for vegetation plots), selective logging and debarking of trees for making beehives, resulting in the death of the affected woody plant species, has potentially the largest influence on chimpanzee plant food and nesting tree abundance. Selective logging threatened $P$. angolensis and P. tinctorius. Illegal beekeeping threatened J. globiflora and B. speciformis because local people around MUE debark these tree species to make local beehives using the bark. However, all these activities often are selective towards certain preferred woody species, and initially do not impact abundance of plant species (Brown and Gurevitch 2004). The selective nature of these activities may explain why the abundance of chimpanzee plant food and nesting tree species did not differ across survey sites with different human disturbance levels.

Furthermore, we found that riparian forests had significantly higher chimpanzee plant food species richness compared to miombo woodlands and wooded grasslands. Sabo et al. (2005) revealed that riparian habitats do not harbor higher number of species, but rather support significantly different species from neighboring upland habitats (i.e., habitats along the sides of a river that are slightly higher in elevation and do not contain surface water). In the case of this study, upland habitats were denoted by miombo woodlands and wooded grasslands. High plant species richness in riparian forests has been considered an indication of high levels of biodiversity (Naiman et al. 1993). An array of plants comprising herbs, grasses, lianas, vines, shrubs, and trees, grow in riparian forests, as was observed in this study. Therefore, riparian forests are of major conservation concern due to the support these habitats provide for a large number of species (Sabo et al. 2005). In addition, these habitats can act as corridors between isolated habitats and play important roles in facilitating movement and migration of animals, providing shelter and maintaining biodiversity (Naiman et al. 1993). Despite the importance and ecological relevance of riparian forests, human encroachment through agricultural activities is an 
ChimpanzeE, DisturbanCE AND ResourCes

324 important threat to these habitats in MUE. During this study, we observed people establishing

325 farms along the riverbanks in the highly disturbed survey site (Mapalamane), thereby

326 encroaching and diminishing the quality of these habitats. In this study we were not able to

327 quantify the extent to which these habitats have been reduced or even disappeared, however

328 future studies that integrate remote sensing easily could calculate reliable estimates (see Hansen

329 et al. 2013). While riparian forests are more threatened by farming activities, miombo woodlands

330 and wooded grasslands are threatened by logging, debarking of trees for local beehives, and

331 livestock activities.

332 We also hypothesized that chimpanzee abundance is influenced negatively by human

333 disturbance and predicted that nest counts would be high in areas of low or no human

334 disturbance. Our results indicate that as human disturbance levels increase, there is a decrease in

335 chimpanzee abundance despite resources being plentiful and more diverse in moderately

336 disturbed sites. Based on our results, we argue that resource availability is not the only factor

337 driving chimpanzee population size in moderately disturbed sites. Our results can be explained in

338 the context of the deterring effect from human presence and activities. This arguement is

339 supported by Garriga et al. (2019), who revealed that in the Moyamba district in southwestern

340 Sierra Leone, the presence and the proximity of humans through roads available in chimpanzee

341 habitats negatively influenced chimpanzee relative abundance and their distribution due to the

342 risks associated with the likelihood of encountering people. Our results also are consistent with

343 those of Bryson-Morrison et al. (2017), who showed that chimpanzees in a human-dominated

344 landscape of Bossou, Guinea, preferred habitat types both with low human presence and

345 abundant food availability. As reported by Bryson-Morrison et al. (2017), Bossou chimpanzees

346 preferred to travel, rest, and socialize in areas with low human-induced pressure. Our results

347 suggest that human disturbance in chimpanzee habitat may affect chimpanzee spatial and 


\section{ChimpanzeE, Disturbance AND RESOURCES}

temporal distribution, regardless of resource availability, i.e., feeding tree species in our case.

However, not all human activities increase chimpanzee vulnerability to anthropogenic

disturbance. Some studies suggest that chimpanzees can tolerate human disturbance such as agriculture, settlements, and low levels of hunting (Rist et al. 2009; Brncic et al. 2015). This argument is similar to that of Garriga et al. (2019), who found that at larger spatial scales, settlements and human presence did not influence chimpanzee relative abundance. Yet, at a temporal level, they found that chimpanzees tended to reduce their activity at midday when human activity was more prevalent, indicating a certain degree of temporal divergence.

Although we were not able to assess chimpanzee behaviour in relation to human disturbance, we acknowledge that chimpanzees may adjust behaviorally to disturbance. Kühl et al. (2019) argued that human disturbance in chimpanzee habitat not only influences critical resources for chimpanzee survival, but also erodes behavioural diversity. Some anthropogenic features are likely to influence chimpanzee behavioral activities (e.g., feeding, nesting, grouping, etc.) in response to human encounters and pressures exerted in their habitats (Brncic et al. 2015; BrysonMorrison et al. 2016; McLennan et al. 2017). In support of this argument, Yuh et al. (2019) found that chimpanzees avoid nesting in frequently disturbed areas, similar to what may be occurring in MUE. Although chimpanzees are behaviorally flexible and are able to exploit human-influenced habitats (Hockings et al. 2012, 2015; Bryson-Morrison et al. 2016, 2017), anthropogenic activities, especially those that affect habitat integrity, threaten their survival.

Based on our findings, we encourage conservation planners and researchers to conduct extensive regular surveys to examine changes in chimpanzee critical resources over time in relation to levels of anthropogenic disturbance. Researchers should set up gradient studies of proximity to large settlements to examine thresholds for change in wildlife densities. 
Chimpanzee, Disturbance And Resources

371 Furthermore, additional effort should be employed to survey large areas and collect sufficient

372 data that will allow for DISTANCE sampling rather than just nest counts. This will enable

373 conservation planners to understand the causative relationships (i.e., effects of anthropogenic

374 activities on chimpanzee resources and abundance), and opt for appropriate conservation actions

375 to conserve MUE, the important habitat for chimpanzees living outside national parks in western

376 Tanzania.

\section{ACKNOWLEDGMENTS}

378 This work was supported by the Greater Mahale Ecosystem Research and Conservation

379 (GMERC) Project. SPM received additional support from the Rufford Foundation (Grant no. 27075-1). We thank the Tanzania Wildlife Research Institute (TAWIRI), the Commission for

Science and Technology (COSTECH), and Mpanda District Council, for granting permission to conduct this study. We are thankful to field assistants and to the botanist, Yahya Abeid, who helped with identification of plant species. The UCSD/Salk Center for Academic Research and

384 Training in Anthropogeny (CARTA) supports long-term research in the Issa valley.

\section{Literature Cited}

BAlcomb, S. R., C. A. ChAPMAN, AND R. W. WranghaM. 2000. Relationship between chimpanzee (Pan troglodytes) density and large, fleshy-fruit tree density: conservation implications. American Journal of Primatology 51:197-203.

Baldwin, P. J., W. C MCGREW, AND E. G. Tutin. 1982. Wide-ranging chimpanzees at Mt. Assirik, Senegal. International Journal of Primatology 3:367-385.

BASABOSE, A. K. 2005. Ranging patterns of chimpanzees in a montane forest of Kahuzi, Democratic Republic of Congo. International Journal of Primatology 26:33-54. 
Chimpanzee, Disturbance AND Resources

393

394

395

396

397

BASABOSE, A. K., AND J. YAMAGIWA. 2002. Factors affecting nesting site choice in chimpanzees at Tshibati, Kahuzi-Biega National Park: Influence of sympatric gorillas. International Journal of Primatology 23:263-282.

Bonnin, N., C. A. Van Andel, T. J. Kerby, K. A. Piel, L. Pintea, And A. S. Wich. 2018. Assessment of chimpanzee nest detectability in drone-acquired images. Drones 2:17.

Brncic, T., B. Amarasekaran, A. McKennA, R. Mundry, AND H. S. KÜHL. 2015. Large mammal diversity and their conservation in the human-dominated land-use mosaic of Sierra Leone. Biodiversity and Conservation 24:2417-2438.

BROOKS, T. M., ET AL. 2002. Habitat loss and extinction in the hotspots of biodiversity. Conservation Biology 16:909-923.

BROWN, K. A., AND J. GUREVITCH. 2004. Long-term impacts of logging on forest diversity in Madagascar. Proceedings of the National Academy of Sciences of the United States of America 101:6045-6049.

Bryson-Morrison, N., T. MATSUZAWA, AND T. Humle. 2016. Chimpanzees in an anthropogenic landscape: Examining food resources across habitat types at Bossou, Guinea, West Africa. American Journal of Primatology 78:1237-1249.

Bryson-Morrison, N., J. TZANopoulos, T. MAtsuzawa, AND T. Humle. 2017. Activity and habitat use of Chimpanzees (Pan troglodytes verus) in the anthropogenic landscape of Bossou, Guinea, West Africa. International Journal of Primatology 38:282-302.

Buckland, S., D. Anderson, K. Burnham, J. LaAke, D. Borchers, AND L. ThOMAs. 2001. Introduction to distance sampling: estimating abundance of biological populations. Oxford 
Chimpanzee, Disturbance AND Resources

University Press. Oxford, United Kingdom.

415

Carvalho, J. S., C. F. J. Meyer, L. Vicente, AND T. A. Marques. 2015. Where to nest?

Ecological determinants of chimpanzee nest abundance and distribution at the habitat and tree species scale. American Journal of Primatology 77:186-199.

CATFORD, J. A., ET AL. 2012. The intermediate disturbance hypothesis and plant invasions: Implications for species richness and management. Perspectives in plant ecology, evolution and systematics 14:231-241.

Cavada, N., S. Tenan, C. Barelli, And F. Rovero. 2019. Effects of anthropogenic disturbance on primate density at the landscape scale. Conservation Biology 33:873-882.

Chapman, C. A., AND L. J. Chapman. 2000. Constraints on group size in red colobus and redtailed guenons: examining the generality of the ecological constraints model. International Journal of Primatology 21:565-585.

CONNELL, J. H. 1978. Diversity in tropical rain forests and coral reefs. Science 199:1302-1310.

DORAN, D. 1997. Influence of seasonality on activity patterns, feeding behavior, ranging, and grouping patterns in Taï chimpanzees. International Journal of Primatology 18:183-206.

FAHRIG, L. 2003. Effects of habitat fragmentation on biodiversity. Annual Review of Ecology, Evolution, and Systematics 34:487-515.

FoERSTER, S., ET AL. 2018. Feeding habitat quality and behavioral trade-offs in chimpanzees : a case for species distribution models 27:1004-1016.

Fruth, B., N. TAGg, AND F. SteWART. 2018. Sleep and nesting behavior in primates: A review. 
Chimpanzee, Disturbance And Resources

American Journal of Physical Anthropology 166:499-509.

435

436

Fuller, J. L., D. R. Foster, J. S. MCLACHLAN, AND N. DraKE. 1998. Impact of human activity on regional forest composition and dynamics in central New England. Ecosystems 1:76-95.

GARRIGA, R. M. ET AL. 2019. Factors influencing wild chimpanzee (Pan troglodytes verus) relative abundance in an agriculture-swamp matrix outside protected areas. PloS ONE 14:e0215545.

GoODALL, J. 1968. The behaviour of free-living chimpanzees in the Gombe Stream Reserve. Animal Behaviour Monographs 1:161-311.

GoODALL, J. 1962. Nest building behavior in the free ranging chimpanzee. Annals of the New York Academy of Sciences 102:455-468.

HACKEL, J. D. 1999. Community conservation and the future of Africa's wildlife. Conservation Biology 13:726-734.

HAMmer, O., D. HARPER, AND P. RyAn. 2001. PAST: Paleontological Statistics Software Package for Education and Data Analysis. Palaeontologia Electronica 4:1-9.

HANSEN, M. C., ET AL. 2013. High-Resolution global maps of 21st-Century forest cover change. Science 342:850-853.

HANSKI, I. 2011. Habitat loss, the dynamics of biodiversity, and a perspective on conservation. AMBIO 40:248-255.

Hernandez-Aguilar, R. A. 2009. Chimpanzee nest distribution and site reuse in a dry habitat: implications for early hominin ranging. Journal of Human Evolution 57:350-364. 
ChimpanZeE, Disturbance AND Resources

454 Hernandez-Aguilar, R. A., J. Moore, And C. B. Stanford. 2013. Chimpanzee nesting 455 patterns in savanna habitat: Environmental influences and preferences. American Journal of 456

Herrera, J. P., P. C. Wright, E. Lauterbur, L. Ratovonjanahary, And L. L. TAylor. 2011. Primatology 75:979-994.

ITOH, N., AND M. NAKAMURA. 2015. Diet and feeding behaviour. Pp. 227-245 in Mahale Animal Behaviour 83:801-810.

Hockings, K. J., J. R. Anderson, AND T. MAtSuZAWA. 2012. Socioecological adaptations by chimpanzees, Pan troglodytes verus, inhabiting an anthropogenically impacted habitat. The effects of habitat disturbance on lemurs at Ranomafana National Park, Madagascar. International Journal of Primatology 32:1091-1108.

HoCKINGS, K. J., ET AL. 2015. Apes in the anthropocene: flexibility and survival. Trends in Ecology \& Evolution 30:215-222.

Chimpanzees: 50 Years of Research (M. Nakamura, K. Hosaka, N. Itoh, and K. Zamma, eds.). Cambridge University Press. Cambridge, United Kingdom.

JUNKER, J., ET AL. 2012. Recent decline in suitable environmental conditions for African great apes. Diversity and Distributions 18:1077-1091.

KÖSter, N., H. KREFt, J. Nieder, AND W. BARThlott. 2013. Range size and climatic niche correlate with the vulnerability of epiphytes to human land use in the tropics. Journal of

473 Kouakou, C. Y., C. Boesch, AND H. KueHL. 2009. Estimating chimpanzee population size with 474 nest counts: validating methods in Taï National Park. American Journal of Primatology 
Chimpanzee, Disturbance AND Resources

475

476

477

478

479

480

481

482

483

484

485

486

487

488

489

490

491

492

493

494

495

$71: 447-457$.

KÜHL, H. S., ET AL. 2017. The critically endangered western chimpanzee declines by $80 \%$. American Journal of Primatology 79:e22681.

KÜHL, H. S., ET AL. 2019. Human impact erodes chimpanzee behavioral diversity. Science $363: 1453-1455$.

LAST, C., AND B. MUH. 2013. Effects of human presence on chimpanzee nest location in the Lebialem-Mone Forest landscape, Southwest Region, Cameroon. Folia Primatologica $84: 51-63$.

LEENDERTZ, F. H., ET AL. 2006. Anthrax in Western and Central African great apes. American Journal of Primatology 68:928-933.

Lôbo, D., T. LeÃo, F. P. L. Melo, A. M. M. SAntos, And M. TABARELli. 2011. Forest fragmentation drives Atlantic forest of northeastern Brazil to biotic homogenization. Diversity and Distributions 17:287-296.

McCarthy, M. S., J. D. Lester, And C. B. Stanford. 2017. Chimpanzees (Pan troglodytes) flexibly use introduced species for nesting and bark feeding in a human-dominated habitat. International Journal of Primatology 38:321-337.

McLennan, M. R., N. Spagnoletti, And K. J. Hockings. 2017. The implications of primate behavioral flexibility for sustainable human-primate coexistence in anthropogenic habitats. International Journal of Primatology 38:105-121.

MoORE, D. L., AND L. VigiLANT. 2013. A population estimate of chimpanzees (Pan troglodytes schweinfurthii) in the Ugalla Region using standard and spatially explicit genetic capture - 
Chimpanzee, Disturbance AND Resources

recapture methods. American Journal of Primatology 76:335-346.

497

Morgan, D., ET AL. 2018. African apes coexisting with logging: Comparing chimpanzee (Pan troglodytes troglodytes) and gorilla (Gorilla gorilla gorilla) resource needs and responses to forestry activities. Biological Conservation 218:277-286.

MOYER, D., ET AL. 2006. Surveys of chimpanzees and other biodiversity in Western Tanzania. Report to the US Fish and Wildlife Service. The Jane Goodall Institute, Wildlife Conservation Society, UCSD. http://pages.ucsd.edu/ jmoore/publications/HernandezEtAl2006WCSTanz.pdf. Accessed 23 November 2019.

Mwageni, N., R. S. SHEMdOe, AND R. KIUNSI. 2015. Assessment of changes in provision of forest ecosystem goods and services and benefit sharing mechanisms in the Ugalla-Masito Ecosystem: A case of Ilagala and Karago villages in Kigoma Region, Tanzania. International Journal of Biodiversity 7:290-298.

NAIMAN, R. J., H. DECAMPS, AND M. POLlOCK. 1993. The role of riparian corridors in maintaining regional biodiversity. Ecological Applications 3:209-212.

NAKAMURA, M., ET AL. 2013. Ranging behavior of Mahale chimpanzees: a 16 year study. Primates 54:171-182.

NAKAMURA, M., K. HoSAKA, N. ITOH, AND K. ZAMMA. 2015. Mahale chimpanzees: 50 years of research. Cambridge University Press. Cambridge, United Kingdom.

Newton-Fisher, N. E. 1999. The diet of chimpanzees in the Budongo Forest Reserve, Uganda. African Journal of Ecology 37:344-354. 
ChIMPANZEE, DisturbanCE AND RESOURCES

517 NishidA, T. 1968. The social group of wild chimpanzees in the Mahale Mountains. Primates $518 \quad 9: 167-224$.

519 NisHIDA, T. 2012. Chimpanzees of the lakeshore: natural history and culture at Mahale.

520 Cambridge University Press. Cambridge, United Kingdom.

521 NishidA, T., AND S. UEHARA. 1983. Natural diet of chimpanzees (Pan troglodytes

522 schweinfurthii): long-term record from the Mahale Mountains, Tanzania. African Study

$523 \quad$ Monographs 3:109-138.

524 Ogawa, H., M. YoshiKawa, AND G. IDANI. 2013. The population and habitat preferences of 525 chimpanzees in non-protected areas of Tanzania. Pan Africa News 20:1-5.

526 Piel, A. K., N. Cohen, S. Kamenya, S. A. Ndimuligo, L. Pintea, And F. A. Stewart. 2015 a.

527 Population status of chimpanzees in the Masito-Ugalla Ecosystem, Tanzania. American $528 \quad$ Journal of Primatology 77:1027-1035.

529 Piel, A. K., A. Lenoel, C. Johnson, And F. A. Stewart. 2015b. Deterring poaching in western 530 Tanzania: The presence of wildlife researchers. Global Ecology and Conservation 3:188$531 \quad 199$.

Piel, A. K., P. Strampelli, E. Greathead, R. A. Hernandez-Aguilar, J. Moore, And F. A. 533 STEWART. 2017. The diet of open-habitat chimpanzees (Pan troglodytes schweinfurthii) in 534 the Issa valley, western Tanzania. Journal of Human Evolution 112:57-69.

535 Piel A.K., AND F.A. Stewart. 2014. Census and conservation status of chimpanzees (Pan 536 troglodytes schweinfurthii) across the Greater Mahale Ecosystem. Report submitted to The 537 Nature Conservancy, USA. 74 p. 
ChimpanZeE, Disturbance AND Resources

538

539

540

PINTEA, L. 2012. Modeling potential conflict between agricultural expansion and biodiversity in the Greater Mahale Ecosystem, Tanzania. Report to Africa Biodiversity Collaborative Group. The Jane Goodall Institute. http://www.abcg.org/action/document/show?document_id=357. Accessed 2 November 2019.

Plumptre, A. J. ET AL. 2010. Eastern chimpanzee (Pan troglodytes schweinfurthii): Status survey and conservation action plan 2010-2020. Gland, Switzerland: IUCN. 52p

Plumptre, A. J., AND V. ReYNOLDS. 1997. Nesting behavior of chimpanzees: implications for censuses. International Journal of Primatology 18:475-485.

RANDS, M. R. W., ET AL. 2010. Biodiversity conservation: challenges beyond 2010. Science 329:1298-1303.

Rist, J., E. J. MiLner-Gulland, G. Cowlishaw, AND J. M. RowCLiffe. 2009. The importance of hunting and habitat in determining the abundance of tropical forest species in Equatorial Guinea. Biotropica 41:700-710.

Rothman, J. M., A. N. Pell, E. S. Dierenfeld, And C. M. Mccann. 2006. Plant choice in the construction of night nests by gorillas in the Bwindi Impenetrable National Park, Uganda. American Journal of Primatology 68:361-368.

SABO, J., ET AL. 2005. Riparian zones increase regional species richness by harboring different, not more, species. Ecology 86:56-62.

SHAPIRO, S. S., AND M. B. WILK. 1965. An analysis of variance test for normality (complete samples)†. Biometrika 52:591-611. 
ChimpanzeE, DisturbanCE AND RESOURCES

559

560

561

562

563

564

565

566

567

568

569

570

571

572

573

574

575

576

577

578

579

StEVENSON, P. R. 2001. The relationship between fruit production and primate abundance in Neotropical communities. Biological Journal of the Linnean Society 72:161-178.

Stewart, F. A., A. K. PIEL, AND W. C. MCGreW. 2011. Living archaeology: Artefacts of specific nest site fidelity in wild chimpanzees. Journal of Human Evolution 61:388-395.

TAWIRI. 2018. Tanzania chimpanzee conservation action plan 2018-2023. Tanzania Wildlife Research Institute. http://tawiri.or.tz/wp-content/uploads/2018/07/Tanzania-ChimpanzeeConservation-Action-Plan-2018.pdf. Accessed 6 November 2019.

WatTs, D. P., K. B. Potts, J. S. LWAnga, And J. C. Mitani. 2012a. Diet of chimpanzees (Pan troglodytes schweinfurthii) at Ngogo, Kibale National Park, Uganda, 1. diet composition and diversity. American Journal of Primatology 74:114-129.

Watts, D. P., K. B. PotTs, J. S. Lwanga, And J. C. Mitani. 2012b. Diet of chimpanzees (Pan troglodytes schweinfurthii) at Ngogo, Kibale National Park, Uganda, 2. temporal variation and fallback foods. American Journal of Primatology 74:130-144.

WiLfred, P., AND A. MACCOLL. 2014. The pattern of poaching signs in Ugalla Game Reserve, western Tanzania. African Journal of Ecology 52:543-551.

WILKINSON, D. M. 1999. The disturbing history of intermediate disturbance. Oikos 84:145-147.

Willig, M. R., AND S. J. PreSLey. 2018. Biodiversity and disturbance. Pp. 45-51 in The Encyclopedia of the Anthropocene (D. A. Dellasala \& M. I. Goldstein, eds.). Elsevier, Amsterdam, Netherlands.

Wrangham, R.W. 1975. Behavioural ecology of chimpanzees in Gombe National Park, Tanzania. Ph.D thesis, Cambridge University. Cambridge, United Kingdom. 
ChimpanZeE, Disturbance AND Resources

580 Yoshikawa, M., AND H. OGAwA. 2015. Diet of savanna chimpanzees in the Ugalla Area, 581 Tanzania. African Study Monographs 36:189-209.

582 Yoshikawa, M., H. Ogawa, T. Sakamaki, AND G. IDANI. 2008. Population density of 583 chimpanzees in Tanzania. Pan Africa News 15:17-20.

584 YUH, Y. G., ET AL. 2019. Effects of land cover change on great apes distribution at the Lobéké 585 National Park and its surrounding Forest Management Units, South-East Cameroon. A 13 586 year time series analysis. Scientific Reports 9:1445. 
Chimpanzee, Disturbance And Resources

FigURE LEGENDS

Fig. 1. Map of the four survey sites located in the Masito-Ugalla Ecosystem, western Tanzania

Fig. 2. Variation in average chimpanzee plant food species richness across the four sites of different disturbance levels in the MUE. The averages were calculated from vegetation plots $(\mathrm{n}=$ 80 in Issa Valley, 80 in Mfubasi, 79 in Mlofwesi, and 80 in Mapalamane). Issa Valley = least disturbed site, Mfubasi = mildly disturbed site, Mlofwesi $=$ moderately disturbed site, and 594 Mapalamane = highly disturbed site. The line in the box represents the median and the box the upper and lower quartile, each representing $25 \%$ of data scores. Whiskers are variability of data scores outside the upper and lower quartiles, and points represent outliers. **indicates $P<0.01$, and $* * * P<0.001$ according to Kruskal-Wallis test.

Fig. 3. Variation in average chimpanzee plant food diversity across the four sites of different disturbance levels in the MUE. The averages were calculated from vegetation plots $(\mathrm{n}=80$ in 600 Issa Valley, 80 in Mfubasi, 79 in Mlofwesi and 80 in Mapalamane). Issa Valley = least disturbed 601 site, Mfubasi = mildly disturbed site, Mlofwesi = moderately disturbed site, and Mapalamane = 602 highly disturbed site. The line in the box represents the median and the box the upper and lower 603 quartile, each representing $25 \%$ of data scores. Whiskers are variability of data scores outside the 604 upper and lower quartiles, and points represent outliers. *** indicates $P<0.001$ according to 605 Kruskal-Wallis test.

Fig. 4. Variation in average chimpanzee plant food species richness across vegetation types. The 607 averages were calculated from vegetation plots $(n=6$ in wooded grassland, 176 in miombo 608 woodland and 137 in riparian forest. The line in the box represents the median and the box the upper and lower quartile, each representing $25 \%$ of data scores. Whiskers are variability of data 
ChimpanzeE, DisturbanCE AND ResourCes

610 scores outside the upper and lower quartiles, and points represent outliers. **indicates $P<0.01$, 611 and $* * * P<0.001$ according to Kruskal-Wallis test. 
ChimpanzeE, Disturbance AND RESOURCES

\section{TABLES}

614 Table 1. Chimpanzee diet data summarized from western Tanzania communities. Indirect and

615 direct refer to observation methods.

\begin{tabular}{lllccl}
\hline Site & Vegetation & Method & \# Fecal & \# Species & Reference \\
& & & samples & consumed & \\
\hline Issa Valley & Open habitat & Indirect & 810 & 69 & Piel et al. (2017) \\
Nguye and Bhukalai & Open habitat & Indirect & 465 & 100 & Yoshikawa and Ogawa (2015) \\
Mahale & Forested & Direct & NA & 198 & Nishida and Uehara (1983) \\
Gombe & Forested & Direct & NA & 147 & Wrangham (1975)
\end{tabular}

616 *Indirect methods used fecal analyses and food remains; direct methods used observations

617 through focal follows. 
ChimpanZeE, Disturbance AND Resources

619 Table 2. Human activities recorded across MUE with respective weight of destructive impacts

620 (impact score) on chimpanzee habitat. Impact scores of a particular human activity based on the 621 extent of disturbance the activity is likely to pose on chimpanzee habitat.

\begin{tabular}{|c|c|c|}
\hline Human activities & Signs for identification & Impact score \\
\hline \multirow[t]{2}{*}{ Agriculture } & Cultivated fields & 5 \\
\hline & Cleared areas for farming & 5 \\
\hline \multirow[t]{3}{*}{ Beekeeping } & Commercial beehives & 1 \\
\hline & Illegal beehives & 2 \\
\hline & Debarking tree for beehives & 2 \\
\hline \multirow[t]{2}{*}{ Harvesting medicinal plants } & Peeling of tree barks & 1 \\
\hline & Digging for tree roots & 1 \\
\hline \multirow[t]{2}{*}{ Livestock grazing } & Cattle herds & 3 \\
\hline & Cattle bomas & 4 \\
\hline \multirow[t]{3}{*}{ Logging } & Logging sites & 4 \\
\hline & Cut logs & 2 \\
\hline & Logging stumps & 2 \\
\hline \multirow[t]{2}{*}{ Poaching } & Snares & 1 \\
\hline & Encountered poachers & 2 \\
\hline Settlement & Households & 4 \\
\hline Small fires & Burnt vegetation & 3 \\
\hline
\end{tabular}


ChIMPANZEE, DisturbanCE AND RESOURCES

624 Table 3. Encounter rates of human activities per km walked in each survey site and the severity

625 of disturbance calculated by multiplying the weighted impact scores and the frequency of

626 encounters of each human activity and then summed as an overall measure of severity of human

627 disturbance. The values indicate the rate of encounter of a particular human activities per

628 kilometer walked in different survey sites and at the bottom the values indicate the severity of

629 disturbance.

\begin{tabular}{|c|c|c|c|c|}
\hline Human activity signs & Issa Valley & Mfubasi & Mlofwesi & Mapalamane \\
\hline Cultivated fields & 0.00 & 0.00 & 0.00 & 2.00 \\
\hline Cleared areas for farming & 0.00 & 0.00 & 0.00 & 0.31 \\
\hline Commercial beehives & 0.00 & 0.00 & 2.06 & 0.00 \\
\hline Illegal beehives & 0.06 & 0.81 & 3.56 & 0.44 \\
\hline Debarking tree for beehives & 0.00 & 0.06 & 0.75 & 0.00 \\
\hline Peeling of tree barks & 0.06 & 0.00 & 0.06 & 0.00 \\
\hline Digging for tree roots & 0.00 & 0.00 & 0.00 & 0.13 \\
\hline Cattle herds & 0.00 & 0.31 & 0.13 & 0.63 \\
\hline Cattle bomas & 0.00 & 0.13 & 0.06 & 0.50 \\
\hline Logging sites & 0.13 & 0.31 & 0.81 & 0.19 \\
\hline Cut logs & 0.00 & 0.44 & 0.69 & 0.00 \\
\hline Logging stumps & 0.00 & 0.25 & 1.13 & 0.19 \\
\hline Snares & 0.19 & 0.00 & 0.38 & 0.00 \\
\hline Encountered poachers & 0.00 & 0.13 & 0.00 & 0.00 \\
\hline Households & 0.00 & 0.00 & 0.00 & 2.88 \\
\hline Burnt vegetation & 0.31 & 0.00 & 0.13 & 0.00 \\
\hline
\end{tabular}


Chimpanzee, Disturbance And Resources

Severity of disturbance

29

77

294

465

Disturbance category

\section{Least}

Mildly

Moderately

Highly

disturbed

disturbed

disturbed

disturbed

630 
ChIMPANZEE, DisturbanCE AND RESOURCES

632 Table 4. Average, minimum, maximum and the sum as well as relative proportions of number of 633 nests observed per plant species that chimpanzees selected for nesting across all survey sites 634 within Masito-Ugalla Ecosystem.

\begin{tabular}{|c|c|c|c|c|c|}
\hline Nesting plant species & Min & Mean & Max & Sum & $\%$ \\
\hline Albizia adianthifolia & 3 & 3 & 3 & 3 & 1.5 \\
\hline Albizia glaberrima & 1 & 1 & 1 & 1 & 0.5 \\
\hline Brachystegia boehmii & 1 & 7.4 & 16 & 67 & 33 \\
\hline Brachystegia bussei & 1 & 2.3 & 3 & 7 & 3.4 \\
\hline Brachystegia microphylla & 1 & 2 & 3 & 6 & 3 \\
\hline Brachystegia sp & 2 & 2 & 2 & 4 & 2 \\
\hline Brachystegia speciformis & 1 & 3.7 & 8 & 11 & 5.4 \\
\hline Combretum molle & 2 & 2.7 & 4 & 8 & 3.9 \\
\hline Julbernadia globiflora & 1 & 1.7 & 2 & 5 & 2.5 \\
\hline Julbernadia unijugata & 1 & 2.6 & 7 & 49 & 24 \\
\hline Markhamia obtusifolia & 2 & 2.5 & 3 & 5 & 2.5 \\
\hline Parinari curatellifolia & 1 & 1 & 1 & 1 & 0.5 \\
\hline Pericopsis angolensis & 2 & 2 & 2 & 2 & 1 \\
\hline Psydrax parviflora & 2 & 2 & 2 & 2 & 1 \\
\hline Pterocarpus tinctorius & 2 & 3 & 4 & 6 & 3 \\
\hline Syzygium guineense & 1 & 2.3 & 3 & 14 & 6.9 \\
\hline Uapaca guineensis & 1 & 2 & 4 & 12 & 5.9 \\
\hline
\end{tabular}


ChimpanZeE, DisturbanCE AND RESOURCES

\section{APPENDICES}

638 Appendix 1. A list of chimpanzee plant feeding species identified in the Masito-Ugalla

639 Ecosystem based on direct observations and the compiled diet lists from Issa Valley and Mahale

640 Mountains National Park (Goodall 1968; Wrangham 1975; Nishida and Uehara 1983; Nakamura

641 et al. 2015; Piel et al. 2017).

S/n. Local name

Scientific name

Growth form

\begin{tabular}{|c|c|c|c|}
\hline 1 & Bhufila & Annona senegalensis & Tree \\
\hline 2 & Bhufulu & Vitex doniana & Tree \\
\hline 3 & Bhungogolo & Multidentia crassa & Tree \\
\hline 4 & Bhunkukuma & Grewia flavescens & Shrub \\
\hline 5 & Bhusantu & Ximenia americana & Shrub \\
\hline 6 & Bhusungunimba & Flacourtia indica & Shrub \\
\hline 7 & Buhono & Pseudospondias microcarpa & Tree \\
\hline 8 & Bwaje & Strychnos spinosa & Tree \\
\hline 9 & Ighoghola & Aspilia mossambicensis & Herb \\
\hline 10 & Igongo & Sclerocarya birrea & Tree \\
\hline 11 & Ijubilha & Baphia capparidifolia & Liana \\
\hline 12 & Ikolyoko 1 & Voacanga africana & Tree \\
\hline 13 & Ikolyoko 2 & Tabernaemontana pachysiphon & Tree \\
\hline 14 & Ikome & Strychnos pungens & Tree \\
\hline 15 & Ikonjogholo & Oncinotis tenuiloba & Liana \\
\hline
\end{tabular}


Chimpanzee, Disturbance And Resources

16 Ikubilha

$17 \quad$ Ikuku 1

$18 \quad$ Ikuku 2

19 Ikuku 3

20 Ikusu

$21 \quad$ Ilombo

22 Isomang'ombe

23 Iswe

24 Itambuka

25 Itesa

26 Itungulu

27 Kabamba

28 Kabhumbu

29 Kafunampasa

$30 \quad$ Kagera 1

$31 \quad$ Kagera 2

32 Kagobhole

33 Kahefu

34 Kahembegwasya

35 Kajimonsole

36 Kakubhabholo

37 Kakusufikinyia

38 Kampandampanda
Ficus sur

Tree

Ficus sonderi

Ficus sycomorus

Ficus glumosa

Uapaca kirkiana

Saba comorensis

Blepharis buchneri

Pennisetum purpureum

Dalbergia malangensis

Commelina africana

Aframomum mala

Julbernadia globiflora

Lannea schimperi

Albizia glaberrima

Brachystegia microphylla

Brachystegia sp

Ziziphus abyssinica

Celtis africana

Thevetia peruviana

Ficus sp

Sterculia tragacantha

Uapaca guineensis

Canthium burtii
Grass

Tree

Tree

Tree

Tree

Liana

Herb

Liana

Herb

Herb

Tree

Tree

Tree

Tree

Tree

Tree

Tree

Herb

Tree

Tree

Tree

Shrub 
Chimpanzee, Disturbance And Resources

\section{Kamwibi}

40 Kankolokombe

41 Kankundu

42 Kansonsokemba

43 Kantapansima

44 Kasolyo

$45 \quad$ Lingogha

46 Linkumbwe

$47 \quad$ Linselele

48 Linsilu

49 Lintonga

$50 \quad$ Lujongololo 1

51 Lujongololo 2

52 Lujongololo 3

53 Lukosho

54 Lulobhe

55 Lulumasha

56 Lulyolwakanga

57 Lulyolwakape

58 Lumpululu

59 Luntafwanengwa 1

60 Luntafwanengwa 2

61 Luntafwanengwa 3
Psydrax parviflora

Ficus asperifolia

Strychnos madagascariensis

Hewittia sp

Toddalia asiatica

Garcinia huillensis

Leea guineensis

Clerodendrum schweinfurthii

Smilax anceps

Pteridium aquilinum

Strychnos cocculoides

Artabotrys monteiroae

Uvaria angolensis

Monanthotaxis poggei

Ampelocissus abyssinica

Uapaca nitida

Pycnanthus angolensis

Margaritaria discoidea

Psychotria peduncularis

Ceropegia sp

Keetia venosa

Keetia guenzii

Keetia ferruginea
Tree

Climber

Tree

Climber

Liana

Tree

Herb

Herb

Herb

Herb

Tree

Climber

Liana

Liana

Climber

Tree

Tree

Shrub

Herb

Herb

Shrub

Shrub

Shrub 
Chimpanzee, Disturbance AND Resources

62 Lusanda

$63 \quad$ Lusisi

64 Mhefu

65 Mhololo

66 Mjimo

67 Mjonso

68 Mkibugwesimbwa

69 Mkobegana

$70 \quad$ Mkoma

$71 \quad$ Mkombelonda

$72 \quad$ Mkote

$73 \quad$ Mkubwa

$74 \quad$ Mkuni

75 Mlama

76 Mlembela

77 Mlulu

78 Mlyansekesi

79 Mninga

80 Mnyenye

81 Mpatwe

82 Mpila

83 Mpongolela

84 Msabasaba 1
Phoenix reclnata

Tamarindus indica

Trema orientalis

Ficus lutea

Ficus thonningii

Vernonia amygdalina

Cordia millenii

Ficus ottoniifolia

Brachystegia bussei

Tarenna pavettoides

Phyllanthus reticulatus

Hexalobus monopetalus

Pleurostylia africana

Combretum molle

Anthonotha noldeae

Ficus artocarpoides

Synsepalum brevipes

Pterocarpus angolensis

Brachystegia boehmii

Paullinia pinnata

Landolphia owariensis

Deinbollia fulvotomentella

Syzygium guineense
Palm tree

Tree

Tree

Tree

Tree

Tree

Tree

Tree

Tree

Tree

Shrub

Tree

Tree

Tree

Tree

Tree

Tree

Tree

Tree

Climber

Liana

Tree

Tree 
ChimpanZeE, Disturbance AND Resources

\begin{tabular}{|c|c|c|c|}
\hline 85 & Msabasaba 2 & Syzygium cordatum & Tree \\
\hline 86 & Msakansaka & Bauhinia thonningii & Tree \\
\hline 87 & Mshindwi & Anisophyllea boehmii & Tree \\
\hline 88 & Msomombo & Tinospora caffra & Climber \\
\hline 89 & Msongati & Diplorhynchus condylocarpon & Tree \\
\hline 90 & Msubhu & Dombeya rotundifolia & Tree \\
\hline 91 & Mtimpu & Antidesma venosum & Tree \\
\hline 92 & Mtobho & Azanza garckeana & Tree \\
\hline 93 & Mtulu & Brachystegia spiciformis & Tree \\
\hline 94 & Mtunu & Harungana madagascariensis & Tree \\
\hline 95 & Mubhula & Parinari curatellifolia & Tree \\
\hline 96 & Mwako & Julbernadia unijugata & Tree \\
\hline 97 & Mwenje & Pterocarpus tinctorius & Tree \\
\hline 98 & Ntalali & Vitex mombasae & Tree \\
\hline 99 & Ntutami & Ficus cyathistipula & Tree \\
\hline 100 & Omoji & Costus afer & Herb \\
\hline 101 & Sihama & Dioscorea sp & Climber \\
\hline 102 & Sitalya & Zanha africana & Tree \\
\hline
\end{tabular}




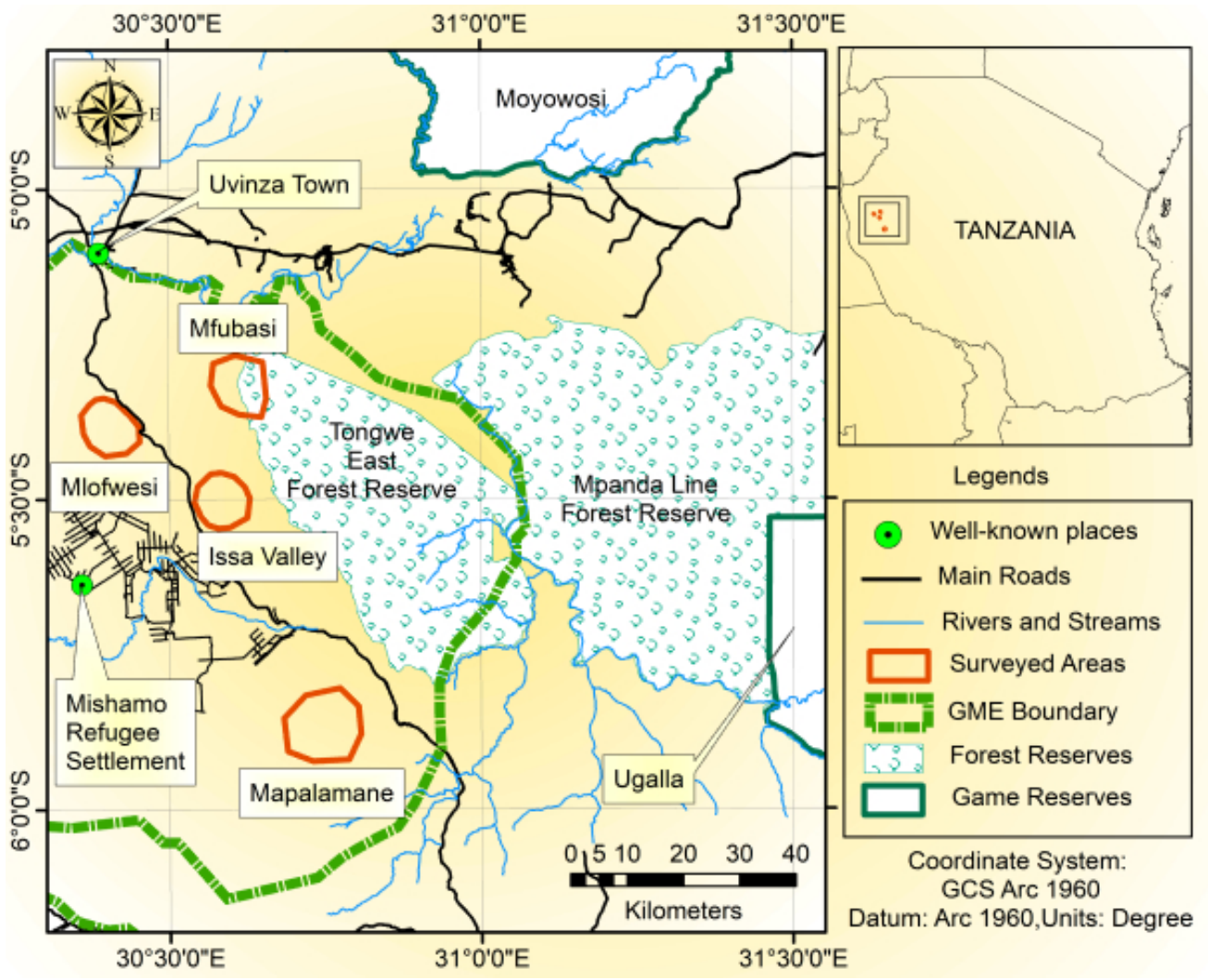

Figure 1

$160 \times 129 \mathrm{~mm}(96 \times 96 \mathrm{DPI})$ 


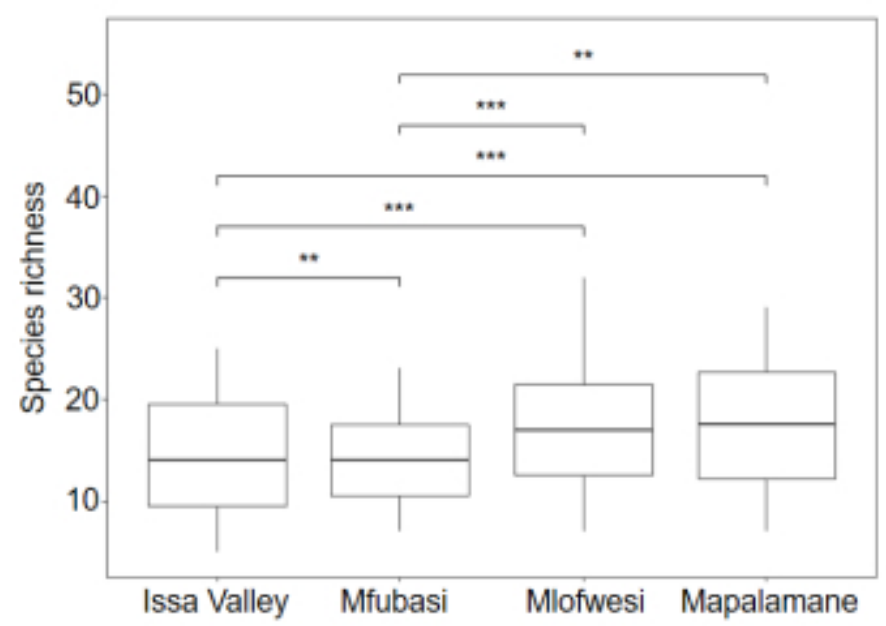

Figure 2

$89 \times 64 \mathrm{~mm}(96 \times 96 \mathrm{DPI})$ 


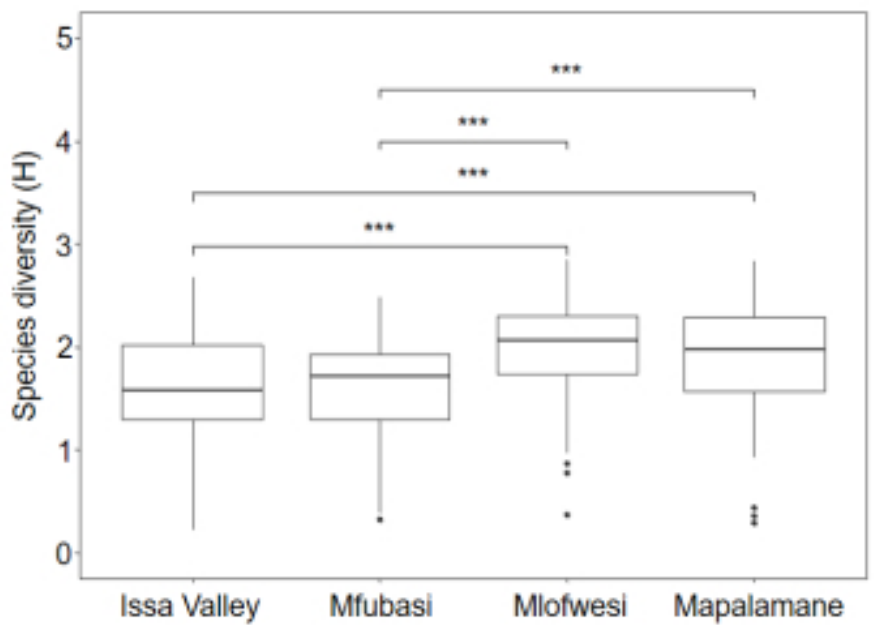

Figure 3

89x64mm (96 x 96 DPI) 


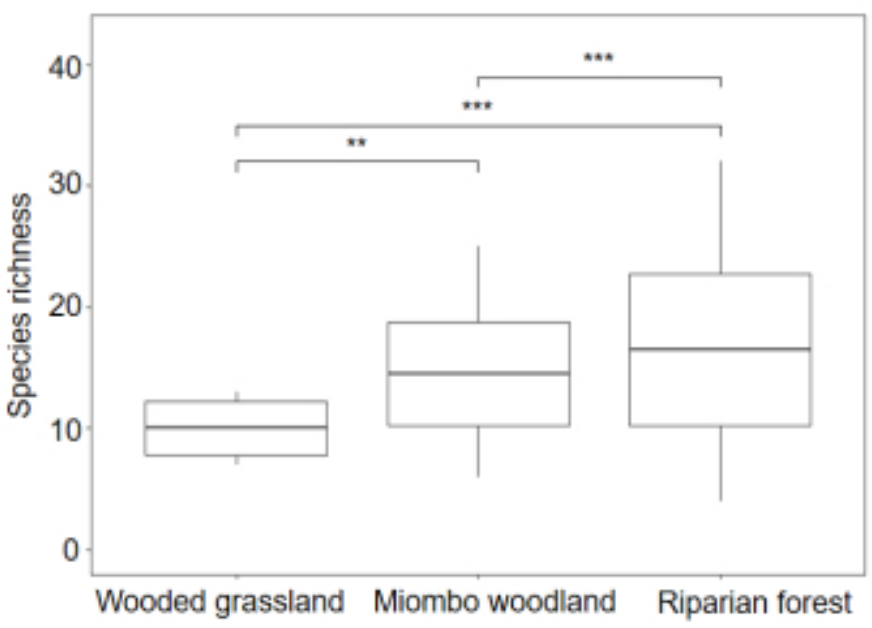

Figure 4

$89 \times 64 \mathrm{~mm}(96 \times 96 \mathrm{DPI})$ 


\title{
Journal of Mammalogy FINAL MANUSCRIPT REVIEW
}

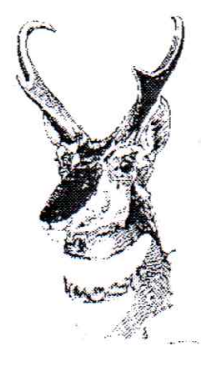

\author{
Manuscript Author: Simula P. Maijo \\ Manuscript Number: JMAMM-2020-054.R3 \\ Return this form within 2 weeks. Your manuscript in the Journal of Mammalogy likely will be \\ delayed in publication if you fail to approve each point and return this form.
}

The Editorial Staff of the Journal of Mammalogy needs your help in maintaining the highest standards of presentation and clarity. Remember, the future value of your contribution rests largely with you.

Your paper is scheduled to be published in the issue of Journal of Mammalogy noted above, pending - your approval of my editorial mark-up,

- certification that you have checked carefully references, scientific names, and data accuracy,

- receipt of your revised manuscript in Scholar One.

Please indicate below that you have attended to each point by initialing each item:

I approve editorial changes on the attached mark-up or in editor's comments, or I have returned the manuscript with explanations for alternate changes that retain my intended meaning.

I checked queries of the Journal Editor and changed items on my revised manuscript where additional information was requested of me.

I checked and corrected each citation for completeness and format and have confirmed that citations in the text are in the Literature Cited, and vice versa.

I checked accuracy and spelling of each scientific name.

I checked accuracy of all data points in text, tables, and figures.

Your signature

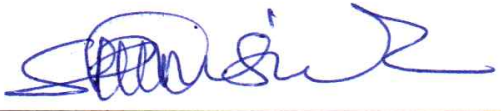

Date: July 25, 2020

Thank you for your time and attention to these final details. I look forward to seeing your paper published in the Journal of Mammalogy.

\section{Please upload this form as Supporting Information when submitted your revised manuscript.}

Alternatively, you may return it to jmammal.editorialoffice@oup.com 